\title{
Research on Rural Regeneration of Northern Mountains Based on Polymorphic Fusion — Taking Laoyu Village as an Example
}

\author{
Gui-ju Lv ${ }^{1}$, Da-liang Liu ${ }^{3}$, Ming-yuan Zhao ${ }^{2}$, Lan-yong Zhao ${ }^{2,}$ * \\ ${ }^{1}$ College of Horticultural Science and Engineering, Shandong Agricultural University, Taian, China \\ ${ }^{2}$ College of Forestry, Shandong Agricultural University, Taian, China \\ ${ }^{3}$ College of Art, Shandong Jianzhu University, Jinan, China
}

\section{Email address:}

sdzly369@163.com (Lan-yong Zhao)

${ }^{*}$ Corresponding author

\section{To cite this article:}

Gui-ju Lv, Da-liang Liu, Ming-yuan Zhao, Lan-yong Zhao. Research on Rural Regeneration of Northern Mountains Based on Polymorphic Fusion — Taking Laoyu Village as an Example. American Journal of Civil Engineering. Vol. 5, No. 6, 2017, pp. 358-364. doi: $10.11648 /$ j.ajce. 20170506.17

Received: October 11, 2017; Accepted: November 3, 2017; Published: November 20, 2017

\begin{abstract}
Sustainable regeneration is a way of rejuvenating and revitalizing the run-down areas to spring to life and become vibrant again by their own efforts. On the basis of interpreting regeneration theory and rural development, this paper analyzes the difficulties and possibility in northern part of rural mountain areas, taking Laoyu Village in the middle of Shandong province mountain area as an example. It also points out the characteristics of regeneration theory in the rural development of northern mountain areas through the characteristics of rural environment and the core of regeneration mode. It explores the concept of rural regeneration and planning design strategy based on rural characteristics.
\end{abstract}

Keywords: Rural Landscape, Rural Generation, Landscape Characteristics, Northern Mountain Area

\section{Introduction}

China is a society with agricultural civilization, thus village is not only the remote origin and base of our rural life, but also a place that accumulating the essence of traditional Chinese culture. Mr. Nan Huaijin has said that the aim of reading thousands of years' history is nothing more than to become rich and famous; The truth of philosophy that has been pursued for too many years can be nothing but the life of poetry, wine and countryside. Countryside is an idyllic dream of Chinese people, which is thought to possess the order of family ethics, the thriving of folk craft, the poetic scene of bridges and flowing water, the amiable rural scenery, the traditional rural culture, the idyllic way of lifestyle. All of these constitute the idyllic dream of Chinese people.

In the process of urban-rural integration, villages carry on various forms: different kinds of industries, many themes, multiple cultures and diverse variety of lives, facilities, subjects, colors, styles and arts. The operation and construction of a village require different specialist knowledge, such as history, architecture, planning, art, ecology, humanities and geography. However, because of factors such as history, economy, culture, society, developer and manager, such forms usually appear to be opposite, contradictory and disharmonious [1]. Coordination of these opposite states to accomplish integrity and harmony is what should be paid attention to. This is the context where polymorphic fusion is come up with.

The characteristic of space regeneration rests in its maintenance of space function after regeneration, or it possesses the bran-new function or form that reflects social phenomenon, economic features, cultural background, technological level and aesthetic requirements of the times, which are the mirror of the present society to some extent [2]-[4]. During the course of urbanization, there are many new towns and buildings in villages. At the same time, some 
former old houses and districts have gradually become vacant or unoccupied spaces as a result of the disappearance and removal of their special functions [5]-[6]. Recycling of space not only saves the cost of construction, but also carries out the site history and inherits regional culture.

Urban space recycling is not a simple process that the new thing replaces the old thing, but it is a reorganization of new space. It should not just consider the previous space, which leads the new design to be immersed in the old space. Furthermore, it also should not make the new buildings towering among the previous urban space [7]-[9]. The new urban space that is different from traditional aesthetics has been created trough the application of new materials, methods, and crafts, which forms a delightful contrast between historic sense of old space and the new meaning and a distinct comparison. Meanwhile, it also shows the the transition that the old buildings have been replaced by the old buildings and their infusion, realizing the co-existence of history and future.

Rural land function has already undertaken great changes [10]-[11]. For example, the architecture courtyard of traditional villages has been transformed from living space, cluttered space and cultured space to planting space, tea space and gum space. What's more, the quality and artistic conception of landscape have been attached great importance to. Another example is that rural landscape has changed from growing plants to multiple rural landscape, and becomes more delicate and modernized. As a result, the regeneration development of grounding function is a major target for rural development. The inheritance and development of villages have gradually boosted through communication, coordination and internet, rather than an arbitrary way of dissevering the regional characteristics. The change of rural landscape is not limited in the preservation of the present and the past, but it stresses the refreshment of grounding's functional structure based on the master of future to improve people's living environment. Function and form are inseparable with each other, for the extension of function will definitely lead to the change of form. There are three ways of dealing due to its grounding nature and function.: protection, change and new-brand design (Figure 1).

With local culture as its origin, rural development has integrated with science and art from different subjects, such as planning, ecology, psychology and art, injecting it with modern life factors and fashion tourism factors. With the development of the grounding function as its main goal, it meets the material and spiritual consumption needs of the modern people without the destroying of the local human context and living habits. In addition, it emphasizes the harmonious coexistence of human and nature, urban people and rural people, to achieve the inheritance and development rural culture with characteristics of times, while realizing the mutual development between rural economy and cultural life.

\section{Inheritance}

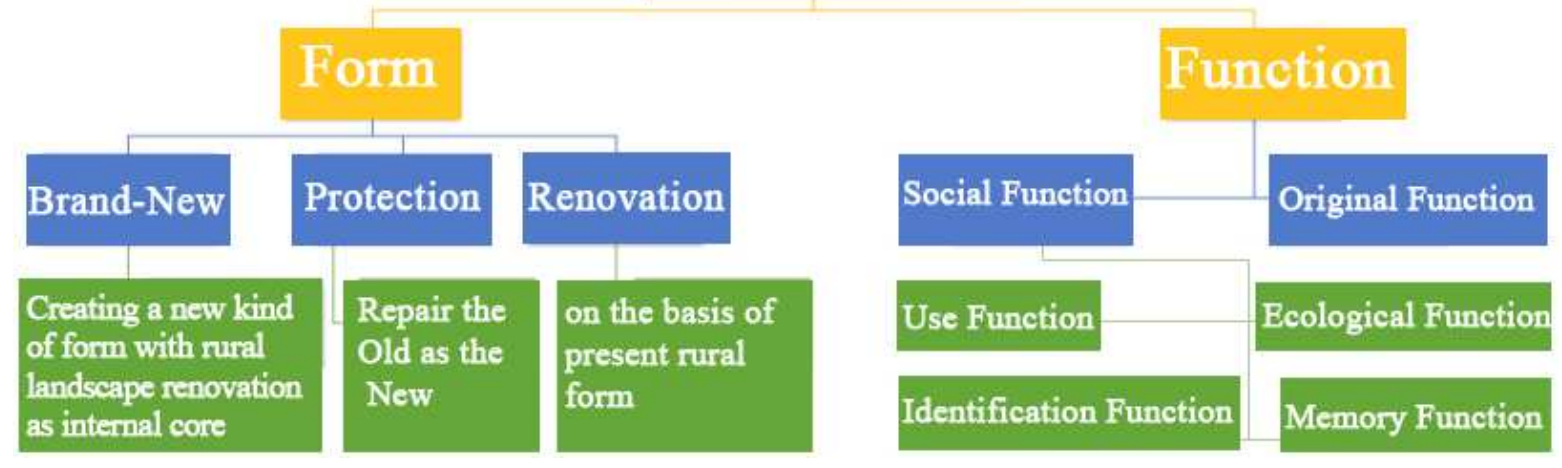

Figure 1. Inheritance of Rural Forms and Functions.

\section{Difficulty and Possibility of Rural Development in Northern Mountain Area}

\subsection{Difficulty of Rural Development in Northern Mountain Area}

At present, prominent achievements have been made in the rural construction, forming almost ten modes of development [12]. They are: industrial development model of Yonglian Village in Nanfeng Town, Zhangjiagang, Jiangsu Province; the ecological protection model of Gaojiatang Village, Shanchuan Town, Anji County, Zhejiang Province; the intensive model in suburbs representing by Liugang Town, Songjiang District, Shanghai; the social comprehensive treatment mode of Guangfa Village, Gongpengzi Town, Songyuan, Jilin Province; cultural inheritance mode of Pingle Village, Pingle Town, Mengjin County, Luoyang, Henan Province; fishing developing mode of Fengmasan Village, Hengli Town, Nansha District, Guangzhou, Gongdong Province; grassland farm mode of Naoganhadagacha, Haoletugaole County, Xiwuzhumuqin Qi, Xilin Gol League, Inner Mongolia; environmental remediation model of Hongyan Village, Lotus Town, Gongcheng Yao People Autonomous County, Guangxi Zhuang Autonomous Region; leisure tourism mode of Jiangwan Town, Wuyuan County, Jiangxi Province; efficient agricultural mode of Sanping 
Village, Pinghe County, Zhangzhou, Fujian Province. In addition, the soil depletion in northern mountain area, the complex terrain, lack of water resources, traffic inconvenience and other reasons lead to the agricultural development, while the forestry or industry development is unrealistic. The biggest advantage of the mountain resources are the natural ecological environment and geographical characteristics of the living landscape. Villages should fully make use of the advantages of resources and make it as a fundamental condition, integrating into the methods which is a combination of science and art with the inheritance of creation by designers based on planning, ecology, culture, psychology, aesthetics and other strategies. Thus, the vitality of villages will be stimulated.

\subsection{Possibility of Rural Development in Northern Mountain Area}

In general, the natural scale of the mountainous villages is small, and the resource advantages are not obvious. In order to integrate the rich resources and the overall planning of the villages, the rural groups need to be determined as the designing object according to the natural geographical features of the countryside and the inner material and the intangible culture. The village group is divided by the administrative classification of the village, but the similarity of ecological cultural characteristics of natural village and the distance.

There are a large number of villages in the middle of mountain area of Shandong Province. Only in the mountain area of Jinan, there are about 500 villages, distributing among different terrains: middle mountain, low mountains, hilly terraces, basins, piedmont slopes, piedmont and mountain plains. Under the influence of special geographical environment, it has brought about the mountain road traffic inconvenience, the closed information environment, and updating the construction of the slow development dilemma. On the other hand, this phenomenon has also enabled these areas to escape the constructive destruction in the rapid socio-economic development and to make a relatively complete reservation of different traditional types of village. Therefore, compared with the traditional villages and historical and cultural towns with rich cultural and natural resources, the mountain village of cultural resources level is low, but there are still historical stories; although the natural resource level is low, there are still beautiful countrysides; although its protection level is low, there are still part of the elements to protect. Because the protection level is low, our country has more possibilities to develop: tourism, pension, vacation, leisure village, theme manor, bed and breakfast hotel, organic agriculture, participation in agriculture and creator practice.

The possibility of rural development is the creative development building by designer based on the rural ecological and cultural characteristics, and it needs multiple leisure recreational functions. Such as rural campgrounds, wetland parks, outdoor sports parks, small leisure farm, different rural interesting activities in different times: Golden Day, sunflower festival and planting. Mountain village is the local museum that accumulating thousands of years' Chinese farming culture and residential culture. The development of the village should be combined with cultural inheritance, the new form of tourism products, the original rural characteristics and styles will be combined together. As for the traditional villages, the personalized, fashionable products, which is suitable for the development of cultural bed and breakfasts, hotels, country museums, intangible cultural heritage of the public square, the artist studio such as some fashion formats, as well as the public social center book bar and cafe can become an integration. It can experience the local culture, perceive the village's memory, transform the village's living space into a holiday space. If the basic condition of agriculture is better, and there are basic talents of agriculture, agricultural capital support, and representative villages in the agricultural culture region, thus the complex with pastoral, park, agricultural and rural unity of the modern agriculture and pastoral leisure can be developed to protect and display traditional culture, and promote the development of modern agriculture.

\section{Exploration on Regeneration Theory of Rural Development in Northern Mountain Area}

\subsection{Stages of the Perception of Rural Environment}

People's perception of the environment can be divided into two stages (Figure 2). First is the external perception, second is the inner perception. External perception refers to the form perception of the most important elements of the environment, especially the perception of important point, line and plane in the landscape structure system. The inner perception refers to the perception of spatial content, especially the five senses of interaction between space and people in the course of space use. If it reaches the spiritual level, then it is a good state of perception.

The external perception mainly refers to the perception of the landscape structure. The elements of the village have been divided in accordance with the point, line and plane of the landscape structure as in the figure. Through the statistics on research data analysis of villagers and outsiders' cognitive map, it is found that the main points of mountain rural landscape structure are: old trees, houses, square and open space near the entrance of the main street. The main linear landscape is: the main street and long and winding roadway and open space. The main planar landscape includes mountain and farmland.

Intrinsic perception refers to the perception of the interaction between people and the landscape in the use of space. This inner perception needs to meet the demands of people's various functions and the double needs of people's emotion for the traditional traits of the country and the preference of the landscape with characteristics of the times. 


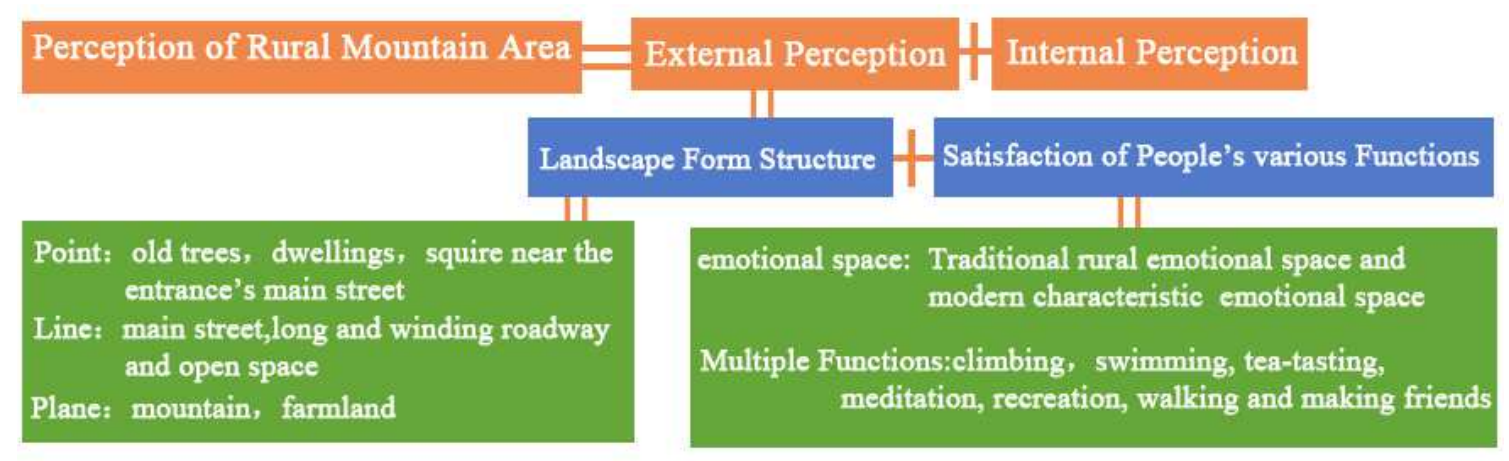

Figure 2. Environment Perception of Mountain Area.

\subsection{Regeneration Characteristics of Villages in Northern Mountain Area}

The development and regeneration of the rural group in the mountain area is the development of rural mountain experiential tourism (Figure 3), which is based on the ecological and cultural background, that is, the regeneration of villages in the mountain area, which equals to the ecological culture background and the creative designing rural experimental form based on the ecological culture and functional space. The main features are as follows:

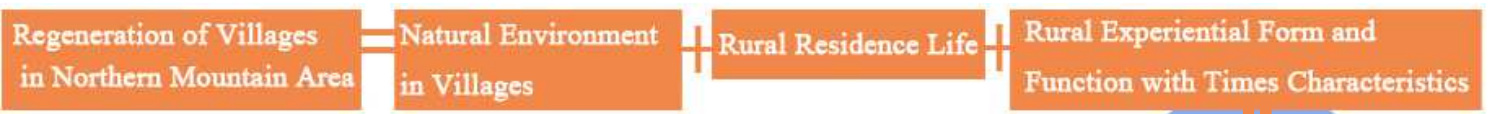

Figure 3. Regeneration of Villages in Northern Mountain Area.

The first feature is the base of the original ecological culture and rural experiential form and space with characteristics of the times. The base of original rural ecological culture is the distinct characteristic that different from plain villages or other regional villages in the rural mountain area of Middle Shandong Province, and also the source for designers for form and function creation. The characteristic of ecological culture is the history of nature and human activity on the earth's surface at different stages. It is around us, and get along and interact with us day and night through the material or spiritual way.

The second feature is the villagers and outsiders. The development of the village should not only serve the villagers but the tourists. Without villagers in the village, there will not be the rural production and activities, the rural feelings and the inner things. Thus the vitality of the village will be weak and short. Without the participation of outsiders, there will be only one way of rural development, hence the economy will severely lag behind. It is the same with the fruit: It will eventually perish if there is only kernel without pulp. It is of great necessity to build up multiple functions to attract the outsiders to join the village, just like making the fresh sweet and lasting. For example, the rural library is not only the place where the villagers learn to improve their knowledge, but also the place where foreign tourists could perceive the countryside.
The third feature is traditional function and fashion function: the original function of the village is simple, including living, planting and simple life. The development of the mountain area needs to be injected into the fashion function: the book bar of artist studio, cafes and other space. The village's living space should be changed into a vacation space. The village should be perceived, add the fresh blood into the vitality of the village.

The forth feature is traditional materials and forms and modern materials and forms. Traditional materials have a distinct regional characteristic and historical vicissitudes. In the process of rural construction, the original materials and forms must be protected. With the improvement of science and technology and people's different variety of aesthetic systems, many modern materials and forms have appeared. People look for modern materials and forms that are in harmony with traditional materials and forms, creating a space with sense of history and modernity, linking the past, present and future of the village.

\subsection{Core of Regeneration Mode in Villages of Northern Mountain Area}

The only path for the development of rural landscape inheritance promoting planning and design on the basis of the individual characteristics of rural landscape. The key to the development of rural landscape inheritance depends on the 
extraction of rural landscape characteristics and the method of planning and design. Its character is to inherit the core of development or it can be called the internal power and the source, while planning and design are the tools and methods for the development of rural landscape heritage, which inherits, develops, innovates, transforms it into a network full of rural personality and temperament. this method of the source of the village heritage, development, innovation, transformation can be flowing in every corner of the country. This method must be derived from the core, integrating into the planning, ecology, art, psychology, geography and other disciplines of science and art. Rural group planning, individual planning and rural space and elements planning, these three

aspects should develop step by step and complement each other. Group planning is the foundation, then the individual village planning can be promoted based on it. Next, the specific space and elements of landscape can be designed. Although the order and emphasis of three aspects are different, their foundation is the characteristics of the village for planning and design.

\section{Exploration on Regeneration Practice of Laoyu Village Group in Xiying Town, Jinan, Shandong Province}

\subsection{Overview of Laoyu Village Group}

According to their geographic location, Laoyu Village, Huajia Valley, Huyuanling, Huajinshao and Houlingzi belong to one rural group, that is, the nature reserve recreation area of the southern mountain area in Jinan. The total area for rural group planning is 5,000 mu (about 3333333.33 squire meters), of which $610 \mathrm{mu}$ (about 406666.67 squire meters) of arable land, and $362.7 \mathrm{mu}$ (about 241800 squire meters) construction land. In order to express more briefly, "Laoyu Village, Huajia Valley, Huyuanling, Huajinshao and Houlingzi" is simplified as "Laoyu rural group" thereafter.

Laoyu rural group is located in a mountain area which belongs to the same range of Mount Tai, and surrounded by mountains on three sites with numerous gullies and ravines. Its scenery is beautiful, full of fresh mountain sightseeing, and forms a sharp contrast with large cities' crowded environment with the hustle and bustle of life, whose natural condition is able to attract visitors. With two hundred years of history in village group, it has formed the unique agricultural civilization and architectural style with "old tile, old stone and old window", showing people a strong beauty of the mountain life.

\subsection{Regeneration Conception}

Through regional landscape of village group and local landscape of individual village, rural planning and design are based on living and the natural environment, thus inherit and develop a layout form and functional space that has advantages in superior location traffic, rich tourist market, high quality ecological environment and the unique living landscape resources, and it is suitable for the use of modern residents and outsiders. It can also promote the leading concept of green sustainable development, embrace the prosperity, return to ecology, build villagers and outsiders ( citizens living, working and traveling in villages), create a harmonious and common prosperous of the modern rural lifestyle, establish a rural tradition and modern integration of the development of life-style tourism, rural economy, life, production, ecology, culture, social harmony development, and create a new village in an all-round way of the $21 \mathrm{st}$ century.

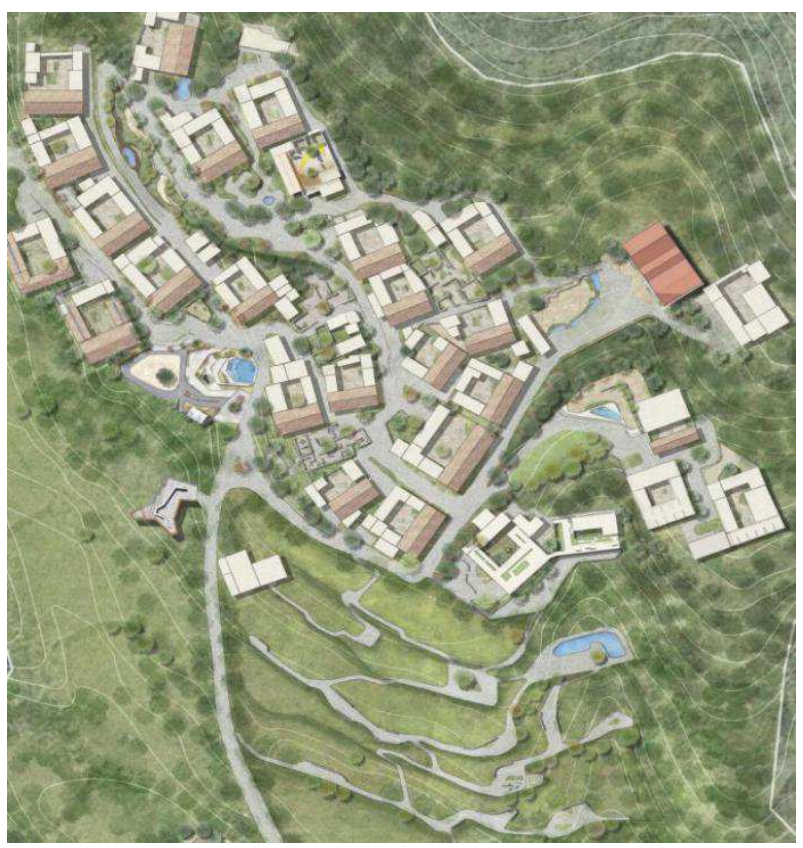

Figure 4. Layout and Structure of Village Group Planning.

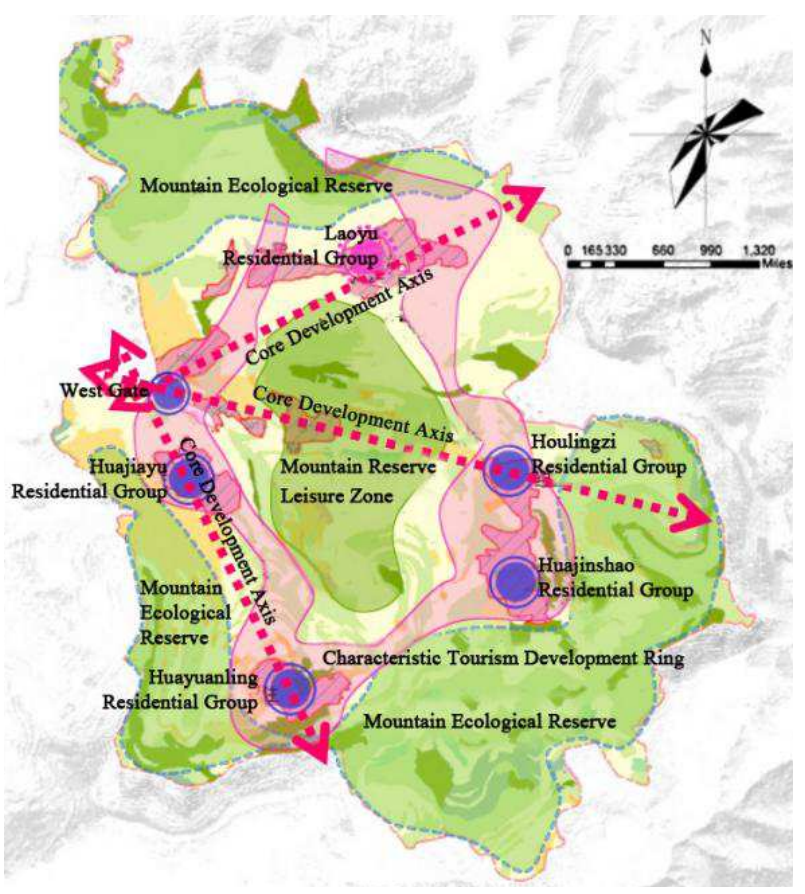

Figure 5. Rural Landscape Plan of Huajia Valley. 


\subsection{Regeneration Strategy}

\subsubsection{Planning Layout and Functional Position Based on Rural Characteristics}

The planning of layout structure is divided into three districts and one ring with a central village and four particular villages (Figure 4). The future development of rural industry and the construction of residential landscape will depend on the main roads and existing core areas in the region.

The three districts are only aiming at the mountain landscape, including two external mountain ecological conservation areas and a mountain recreation area with villages surrounded inside. The ecological environment around Laoyu should be protected, and using construction of mountain ecological conservation to control it. And the mountain recreation area should also carry out ecological conservation of the mountain, and establish a reasonable set of tour trails based on it.

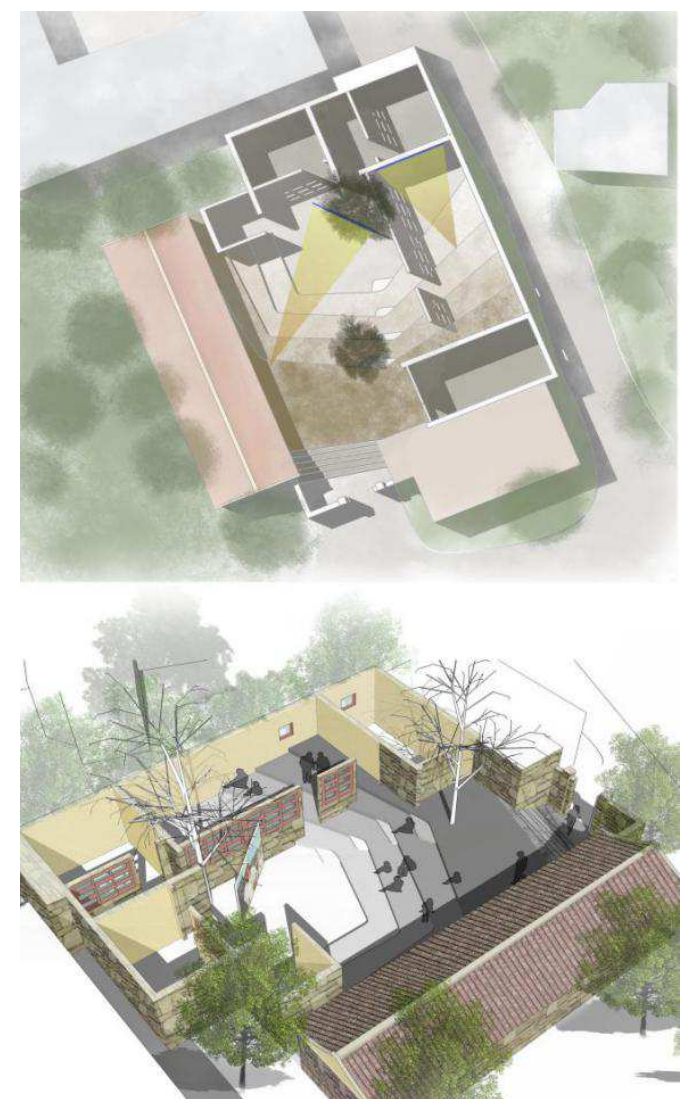

Figure 6. Leisure Cinema Landscape in the Village of Huajia Valley.

First is the characteristic tourism development ring, which is around the center of the functional village - outside the Laoyu Village, relying on the entrance of the west gate, agricultural tourism, fruit and vegetable picking, ornamental flowers field and special residential health and other projects, combined with the relevant service area facilities, Huajia Valley, Huayuanling, Houlingzi and Huajinshao can be constructed as the key construction characteristic tourism development ring, and develop the cultural and leisure health industry.

Three-axis is the distance from the west entrance to Laoyu Village between the west entrance and the door to Houlingzi, and between the west entrance to Huajia Valley, establishing three core development axis. As the core of development, it can lead the tourism and development of other region.

One central village refers to Laoyu Village, which provides the entire rural group's industry and the villagers' living and production with a convenient, comfortable and comprehensive service and leisure function. To serve the villagers and tourists' living and life, it produces a series of functions: education, health care, children's entertainment, fitness, living and living space.

Four characteristic villages refer to the art village of Huajia Valley, which offers some art-related functions: art exhibition, art drawing, art creation, artist design room, art tour and so on. The agricultural landscape positioning refers to the organic agriculture that is a combination of rural concentration and the scattered and experiential agriculture. It has both large-scale agricultural landscape and the garden-style agriculture. Villagers and outsiders live in agricultural environments. Because of the concentrated historical and cultural relics with distinctive regional characteristics of the residential courtyard, market culture space, the main street roadway, performing arts, folk activities, handicrafts, diet and dialects for the development of rural culture tour. Due to its good natural environment, Huajinshao's landscape positioning can be developed for health and fitness.

\subsubsection{Personalized Rural Landscape Design Based on Rural Characteristics}

Huangjia Valley is located in the middle of the Laoyu village group, its northern part is Laoyu Village, the southern part is Huayuanling and the eastern part is Houlingzi. With various kinds of terrains, Huajia Valley has the most changeful terrains among the five villages. Terraces among the mountains have formed various shapes, its natural element is pure, its stone resources are rich, its natural scenery is simple and beautiful, its cultural connotation is abundant, which has great design space.

Based on its characteristics, the rural regeneration landscape which is a combination of art, field and garden (Figure 5). Art is the art of modern, field is the terrace everywhere among the mountains of Huajia Valley, garden is the villagers' home and courtyard. Through the place creation, the earth art and other innovative forms, it can be involved in this place, introducing the art into the village. It can also be constructed into an experimental field which is a combination of modern art and traditional village with the original historical and cultural patterns, street construction structure, architectural form, spatial scale, natural style, interdependent natural ecological cultural landscape and environmental concept.

(1) Art Atmosphere Creation of Leisure Cinema

This design has transformed the courtyard between this building into an open field of theater space, which combines 
the indoor and outdoor space together, thus changing people's feelings of space, enriching the daily activities of the villagers, providing rural living space with new features, injecting the village with the vitality. We can increase the vertical change of the cinema according to the form of terraced steps.

The theater combines community environment, residential gatherings and public events to increase the use of traditional courtyards and find greater possibilities in small spaces. It is an open cultural platform where villagers and tourists in the village can rest and watch movies here, transforming the courtyard into a permanent cultural activity space (Figure 6).

(2) Art Atmosphere Construction of Old Building Reform

The background of the design is the broken wall, placing a transparent glass panel. Glass and stone are like the realistic and unrealistic thing, contrasting with each other. Art groups can use the real village as the background, releasing their imagination and creativity in the drawing board. When the fictional picture is combined with the real historical picture, the new art device is also integrated with the ancient village. This is also a way to inspire people to attach importance to the original site and way of thinking. From the visual and the area of view, this glass panel has minimized the local impact of the original appearance, reflecting the respect and protection of the site.

\section{Conclusion}

Space regeneration is not only the preservation and restoration of the present or the past, it empathizes more on the correct grasp of future changes as the basis, updating the space function, improving the living environment, restoring or maintaining the space is losing or have been lost the function of "times traction". The key problem of regeneration is how to deal with the relationship between "the new" and "the old", how to grasp the relationship of cultural inheritance, historical continuation and social and economic development. Taking the Laoyu Village of the middle of Shandong Province in mountain area as an example, this paper has studied the pattern of rural spatial regeneration and its core. It has explored the rural regeneration design and strategy based on rural characteristics through the practice of regeneration in Laoyu Village group.

\section{References}

[1] Bao Ziting, Zhou Jianyun. Phenomenon, Reasons, and Countermeasures for Contemporary Landscape Decline [J]. City Planning Review. 2014(10)

[2] Zhu Xia, Zhou Yangyue, Shan Zhuoran. Study on Strategy and Path of Rural China Transformation and Renaissance: Under the Context of Rural Subjectivity [J]. Urban Development Studies. 2015(08)

[3] Fang Yangang, Liu Jisheng. Rural Landscape Changes and Its Optimization Strategies: From the Perspective of Ideal Type Narratives [J]. Acta Geographica Sinica. 2012(10)

[4] Shen Mingrui, Zhang Jingxiang. China's Rural Transformation and Revival in the Context of New Urbanization [J]. City Planning Review. 2015(01)

[5] Zheng Wenjun. The Value Cognition and Function Reconstruction of Rural Landscape on Tourism Perspective: Based on the Literatures Analysis [J]. Areal Research and Development. 2013(02)

[6] Yang Rui. Thoughts on Theories and Practice of Landscape Urbanism [J]. Landscape Urbanism. 2009(10)

[7] Chen Xudong, Chen Meiwu, Pan Chunyan. Compound Planning for Countryside Regeneration: From System Improvement to Spatial Governance [J]. Planners. 2016(03)

[8] Ynag Guiqing, Dai Tingxi, Wang Zhen, Huang Huang. Regeneration of Historical Cultural Village under the Perspective of Social Change [J]. Urban Planning Forum | Urban Plan Forum. 2016(05)

[9] Xu Jiangyin, Pan Bingni, Zeng Ying. Regeneration--Promotion of Ecological Industry for Rural Brownfield Revival [J]. 2017(07)

[10] Zhang Xiaoyan. Rural Landscape Construction on the basis of "Beautiful Village" [J]. Art Observation. 2017(08)

[11] Wang Nanxi, Lu Qi. Research on Rural Landscape Value Evaluation Factors and Sustainable Development Method [J]. 2015(12)

[12] Tu Shuangshuang, Long Hualou. Rural restructuring in China: Theory, approaches and research prospect [J]. Journal of Geographical Sciences, 2017(10) 